\title{
MODELS FOR THE SEPARATION OF GLUCOSE/FRUCTOSE MIXTURE USING A SIMULATED MOVING-BED ADSORBER
}

\author{
KENJI HASHIMOTO, SHUJI ADACHI, HIROMITSU NOUJIMA \\ AND HIROKI MARUYAMA \\ Department of Chemical Engineering, Kyoto University, Kyoto 606
}

\begin{abstract}
The continuous separation of a glucose/fructose mixture was experimentally performed using a simulated moving-bed adsorber packed with the $\mathrm{Ca}^{2+}$ ion form of $\mathrm{Y}$ zeolite. In the adsorber, the continuous and countercurrent contact of the liquid stream with the solid adsorbent is simulated by advancing adsorption columns against the fixed inlets and outlets of liquid streams, without actual movement of the solid adsorbent. Two mathematical models, i.e., an intermittent moving-bed and a continuous moving-bed type, are presented for calculating the concentration profiles of glucose and fructose in the simulated moving-bed adsorber. The validity of the models is experimentally confirmed, and a criterion for good separation in the simulated moving-bed adsorber is presented.
\end{abstract}

\section{Introduction}

The most common type of fructose syrup, usually called a high-fructose syrup, contains $42 \%$ fructose, $52 \%$ glucose, and $6 \%$ oligosaccharides on a dry basis, ${ }^{9)}$ and is used in place of sucrose in some foods and beverages. For some purposes, since fructose is sweeter and more soluble in water at low temperatures than glucose, a syrup with 55 to $90 \%$ fructose, called a higher-fructose syrup, is desirable.

Isomerization of glucose to fructose, catalyzed by glucose isomerase, is a reversible reaction with an equilibrium constant of 1.0 at $323 \mathrm{~K} .{ }^{15)}$ Therefore, to produce a syrup containing more than $50 \%$ fructose, a process to separate fructose from the equilibrium mixture is indispensable. A selective adsorption method using ion-exchangers ${ }^{7)}$ seems to be promising for the separation. These methods may be classified into chromatographic and moving-bed operations.

The chromatographic separation process is simple, but has the following disadvantages: ${ }^{4)}$ (i) the whole adsorbent bed is not effectively utilized, (ii) a large amount of desorbent is consumed, (iii) a large difference in the adsorption equilibria between adsorbates is required, and (iv) the operation is discontinuous.

The other type of separation process, which can overcome some of the disadvantages of the chromatographic process, utilizes a simulated moving-bed adsorber. The adsorber can separate glucose and fructose continuously by the counter-current movement of adsorbent to liquid flow. The process was originally developed by Universal Oil Products Co.

\footnotetext{
Received September 1, 1982. Correspondence concerning this aricle should be addressed to K. Hashimoto. H. Noujima is now at Showa Denko K.K., Kawasaki 210 H. Maruyama is at Kawasaki Steel Corp., Mizushima 712
}

$(\mathrm{UOP})^{3)}$ and has been applied to commercial separation processes. Few design methods for this type of adsorber, however, have been reported. The purpose of this study is to present mathematical models for the glucose/fructose separation process utilizing the adsorber, to examine the validity of these models experimentally, and to discuss a criterion for good separation by using the models.

\section{Mathematical Models}

1.1 Basic idea underlying the simulated moving-bed adsorber

Although the simulated moving-bed operation does not include real movement of the adsorbent particles, the operation is more clearly understood in terms of a hypothetical moving-bed adsorber. Figure 1 illustrates schematically the flows of adsorbent and liquid in such an adsorber. Feed and desorbent solutions enter continuously. At withdrawal points of raffinate and extract solutions, a portion of the liquid flowing in the bed is continuously withdrawn and the remainder continues to flow into the next zone. As shown in Fig. 1, the bed is divided into four zones, I to IV, each of which performs a different primary function as described below:

We suppose here that fructose is more strongly adsorbed than glucose. Fructose introduced is adsorbed mostly in zone II and is carried to zones III and IV by the movement of adsorbent particles. Although glucose is weakly adsorbed in zone II, it is mostly passed through zone II and the majority of it is withdrawn by a raffinate stream. Glucose which has been adsorbed in zone II is desorbed in zone III. Most of the fructose adsorbed in zone II is desorbed in zone IV to join the liquid stream passing through 


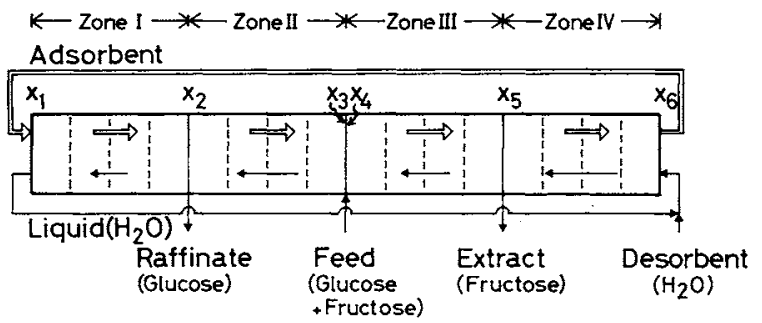

Fig. 1. Schematic representation of a hypothetical movingbed adsorber, and definition of variable vectors $\left(X_{i} ; i=\right.$ $1,2, \cdots, 6$ ).

the zone, and most of the fructose in the liquid stream is recovered in the extract stream. In consequence of the desorption of fructose in zone IV, the adsorbent particles are regenerated and can be recycled to zone I. In zone I, glucose remaining in the liquid stream from zone II is adsorbed. Consequently, the liquid emerging from zone I contains very little of either glucose or fructose, so it is reused as a part of desorbent.

The actual movement of adsorbent particles may cause abrasion of adsorbent and channelling of liquid flow. Without any actual movement of adsorbent, the counter-current movement of liquid and adsorbent can be simulated by the following two operating methods. In one, separate adsorption columns are connected in series and form a closed loop as a whole. In a method developed by UOP, ${ }^{3,5,17)}$ the introduction and withdrawal points are shifted against fixed columns in the direction of the liquid flow. In the other method, the columns are rotated against fixed introduction and withdrawal points in the opposite direction to that of liquid flow. Both methods give the same effect in principle. The latter method was adopted for this study because of its ease of use in experiments of small scale.

To calculate the concentration profiles of glucose and fructose in the simulated moving-bed adsorber, we have developed two models. One is an intermittent moving-bed model, which expresses the actual mode of operation and is useful in the calculation of the transient change of concentration profiles in the adsorber. The other is a continuous moving-bed model, based on the hypothetical movement of adsorbent, and was found to be convenient in the calculation of steady-state concentration profiles in the adsorber.

The following points are assumed in both models: (i) the adsorption isotherms of glucose and fructose are linear and independent of each other, (ii) the adsorption rate process is represented by a lineardriving-force approximation, ${ }^{6,11)}$ (iii) axial dispersion can be ignored, and (iv) the overall mass transfer coefficients of glucose and fructose are the same and do not depend on the rate of liquid flow.

\subsection{An intermittent moving-bed model}

In the operation of the simulated moving-bed adsorber, each adsorption column is considered to be a fixed bed except at the moment of rotating the column. Mass balance equations referring to the concentrations of component $\mathrm{k}$ in mobile phase $C_{\mathrm{k}}$ and in stationary phase $C_{\mathrm{k}}{ }^{*}$ are given by Eqs. (1) and (2), which are set to be positive for the direction of liquid flow.

$$
\begin{aligned}
& \varepsilon_{\mathrm{b}} \frac{\partial C_{\mathrm{k}}}{\partial t}=-v_{\mathrm{n}} \frac{\partial C_{\mathrm{k}}}{\partial z}-K_{\mathrm{f}} a_{\mathrm{v}}\left(C_{\mathrm{k}}-C_{\mathrm{k}}^{*}\right) \\
& \left(1-\varepsilon_{\mathrm{b}}\right) m_{\mathrm{k}} \frac{\partial C_{\mathrm{k}}{ }^{*}}{\partial t}=K_{\mathrm{f}} a_{\mathrm{v}}\left(C_{\mathrm{k}}-C_{\mathrm{k}}{ }^{*}\right)
\end{aligned}
$$

Process time $t$ and axial distance $z$ are normalized by the interval of transportation of adsorption column $T$, and the length of each column $L_{\mathrm{A}}$, respectively. To carry out the numerical calculation stably the partial derivative with respect to time is converted into the forward type of finite difference equation, whereas the derivative for the distance is replaced by the backward type.

$$
\begin{aligned}
\frac{\partial C_{\mathrm{k}}}{\partial \theta} & =\frac{C_{\mathrm{k}}\left(x_{i}, \theta_{j+1}\right)-C_{\mathrm{k}}\left(x_{i}, \theta_{j}\right)}{\Delta \theta} \\
\frac{\partial C_{\mathrm{k}}{ }^{*}}{\partial \theta} & =\frac{C_{\mathrm{k}}{ }^{*}\left(x_{i}, \theta_{j+1}\right)-C_{\mathrm{k}}{ }^{*}\left(x_{i}, \theta_{j}\right)}{\Delta \theta} \\
\frac{\partial C_{\mathrm{k}}}{\partial x} & =\frac{C_{\mathrm{k}}\left(x_{i}, \theta_{j}\right)-C_{\mathrm{k}}\left(x_{i-1}, \theta_{j}\right)}{\Delta x}
\end{aligned}
$$

Then we obtain the following set of finite difference equations.

$$
\begin{aligned}
C_{\mathrm{k}}\left(x_{i}, \theta_{j+1}\right)= & \left(1-\lambda_{\mathrm{n}} \cdot \Delta \theta / \Delta x-\phi \cdot \Delta \theta\right) \cdot C_{k}\left(x_{i}, \theta_{j}\right) \\
& +\phi \cdot \Delta \theta \cdot C_{\mathrm{k}}{ }^{*}\left(x_{i}, \theta_{j}\right) \\
& +\left(\lambda_{\mathrm{n}} \cdot \Delta \theta / \Delta x\right) \cdot C_{\mathrm{k}}\left(x_{i-1}, \theta_{j}\right) \\
C_{\mathrm{k}}{ }^{*}\left(x_{i}, \theta_{j+1}\right)= & \psi_{\mathrm{k}} \cdot \Delta \theta \cdot C_{\mathrm{k}}\left(x_{i}, \theta_{j}\right) \\
& +\left(1-\psi_{\mathrm{k}} \cdot \Delta \theta\right) \cdot C_{\mathrm{k}}{ }^{*}\left(x_{i}, \theta_{j}\right)
\end{aligned}
$$

where

$$
\begin{aligned}
\lambda_{\mathrm{n}} & =v_{\mathrm{n}} T /\left(\varepsilon_{\mathrm{b}} L_{\mathrm{A}}\right) \\
\phi & =K_{\mathrm{f}} a_{\mathrm{v}} T / \varepsilon_{\mathrm{b}} \\
\psi_{\mathrm{k}} & =K_{\mathrm{f}} a_{\mathrm{v}} T /\left\{\left(1-\varepsilon_{\mathrm{b}}\right) m_{\mathrm{k}}\right\}
\end{aligned}
$$

and $\Delta x$ and $\Delta \theta$ are the increments for the $x$ - and $\theta$ directions, respectively. The subscripts $i$ and $j$ represent the $i$-th and $j$-th grid points for the $x$ - and $\theta$ directions.

The following conditions are written for the introduction and withdrawal points located between two adjoining zones:

at the withdrawal point of the raffinate stream

$$
C_{\mathrm{kIII}}=C_{\mathrm{klO}}
$$

at the introduction point of the feed stream

$$
v_{\mathrm{f}} \cdot C_{\mathrm{kf}}+v_{\mathrm{III}} \cdot C_{\mathrm{kIIII}}=v_{\mathrm{II}} \cdot C_{\mathrm{kIIO}} .
$$


at the withdrawal point of the extract stream

$$
C_{\mathrm{kIVl}}=C_{\mathrm{kIIIO}}
$$

at the introduction point of the desorbent stream

$$
v_{\mathrm{I}} \cdot C_{\mathrm{kII}}=v_{\mathrm{IV}} \cdot C_{\mathrm{kIV} 0}
$$

where the subscripts 0 and 1 denote the inlet and outlet of the liquid stream in each zone, respectively. As shown in Fig. 2, $C_{\mathbf{k}}\left(x_{i}, \theta_{j+1}\right)$ and $C_{\mathrm{k}}{ }^{*}\left(x_{i}, \theta_{j+1}\right)$ are calculated explicitly from Eqs. (4), (5), and (7). The calculation is repeated until $\theta=1.0$. At $\theta=1.0, C_{\mathrm{k}}$ and $C_{\mathrm{k}}{ }^{*}$ are rearranged in the direction of the arrows illustrated in Fig. 2. The rearrangement corresponds to rotation of the adsorption columns. Then, the $\theta$ value is reset to zero. The rearrangement of $C_{\mathrm{k}}$ and $C_{\mathrm{k}}{ }^{*}$ values is repeated whenever the $\theta$ value reaches 1.0 .

The increments, $\Delta x$ and $\Delta \theta$, should be selected so that the truncation error may be negligibly small. Selection of 0.1 and 0.02 for $\Delta x$ and $\Delta \theta$, respectively, gave sufficient precision to calculate the profiles under the experimental conditions of this work.

\subsection{A continuous moving-bed model}

It is hypothesized in this model that the adsorbent particles move continuously at the rate of $u_{\mathrm{s}}$, which is defined as $L_{\mathrm{A}} / T$. We can derive analytical solutions which relate $C_{\mathrm{k}}$ and $C_{\mathrm{k}}{ }^{*}$ values at the inlet of each zone to those at the outlet. The mass balance equations at steady state in terms of $C_{\mathrm{k}}$ and $C_{\mathrm{k}}{ }^{*}$, setting to be positive for the direction of the adsorbent movement, are given by Eqs. (8) and (9).

$$
\begin{gathered}
u_{\mathrm{n}} \frac{d C_{\mathrm{k}}}{d z}=K_{\mathrm{f}} a_{\mathrm{v}}\left(C_{\mathrm{k}}-C_{\mathrm{k}}{ }^{*}\right) \\
\left(1-\varepsilon_{\mathrm{b}}\right) m_{\mathrm{k}} u_{\mathrm{s}} \frac{d C_{\mathrm{k}}{ }^{*}}{d z}=K_{\mathrm{f}} a_{\mathrm{v}}\left(C_{\mathrm{k}}-C_{\mathrm{k}}{ }^{*}\right)
\end{gathered}
$$

where $u_{\mathrm{n}}$ represents the superficial velocity of liquid flow in zone $\mathrm{n}$ in the hypothetical moving-bed adsorber and is related to $v_{\mathrm{n}}$ by

$$
u_{\mathrm{n}}=v_{\mathrm{n}}-\varepsilon_{\mathrm{b}} L_{\mathrm{A}} / T
$$

Assuming that $C_{\mathrm{k}}$ and $C_{\mathrm{k}}{ }^{*}$ at the inlet of zone $\mathrm{n}$ are known, that is, $C_{\mathrm{k}}=C_{\mathrm{kn} 0}, C_{\mathrm{k}}{ }^{*}=C_{\mathrm{kn} 0}^{*}$ at $z=0$, Eqs. (8) and (9) can be analytically solved, and $C_{\mathrm{k}}$ and $C_{\mathrm{k}}{ }^{*}$ at the outlet of zone $\mathrm{n}, C_{\mathrm{knl}}$ and $C_{\mathrm{knl}}^{*}$, are given by

$$
\begin{aligned}
C_{\mathrm{knl}}= & \frac{\exp \left\{\alpha_{\mathrm{n}}\left(1-\beta_{\mathrm{nk}}\right) N_{\mathrm{n}}\right\}-\beta_{\mathrm{nk}}}{1-\beta_{\mathrm{nk}}} \cdot C_{\mathrm{kn} 0} \\
& +\frac{1-\exp \left\{\alpha_{\mathrm{n}}\left(1-\beta_{\mathrm{nk}}\right) N_{\mathrm{n}}\right\}}{1-\beta_{\mathrm{nk}}} \cdot C_{\mathrm{kn} 0}^{*} \\
C_{\mathrm{kn} 1}^{*}= & \frac{\beta_{\mathrm{nk}}\left[\exp \left\{\alpha_{\mathrm{n}}\left(1-\beta_{\mathrm{nk}}\right) N_{\mathrm{n}}\right\}-1\right]}{1-\beta_{\mathrm{nk}}} \cdot C_{\mathrm{kn} 0} \\
& +\frac{1-\beta_{\mathrm{nk}} \exp \left\{\alpha_{\mathrm{n}}\left(1-\beta_{\mathrm{nk}}\right) N_{\mathrm{n}}\right\}}{1-\beta_{\mathrm{nk}}} \cdot C_{\mathrm{kn} 0}^{*}
\end{aligned}
$$



Fig. 2. Schematic explanation of the calculation method in an intermittent moving-bed model.

where

$$
\begin{gathered}
\alpha_{\mathrm{n}}=K_{\mathrm{f}} a_{\mathrm{v}} L_{\mathrm{A}} / u_{\mathrm{n}} \\
\beta_{\mathrm{nk}}=u_{\mathrm{n}} /\left\{u_{\mathrm{s}}\left(1-\varepsilon_{\mathrm{b}}\right) m_{\mathrm{k}}\right\}
\end{gathered}
$$

It was found that a new variable $\bar{C}_{\mathrm{k}}{ }^{*}$, defined by Eq. (14), is more convenient than $C_{\mathrm{k}}{ }^{*}$ in solving a set of simultaneous algebraic equations.

$$
\bar{C}_{\mathrm{k}}{ }^{*}=C_{\mathrm{k}}-C_{\mathrm{k}}{ }^{*}
$$

Column vectors defined by Eq. (15) are introduced at the six points shown in Fig. 1.

$$
X_{i}=\left[C_{\mathrm{k} i} \bar{C}_{\mathrm{k} i}^{*}\right]^{T} \quad(i=1,2, \cdots, 6)
$$

The variable vectors $X_{i}(i=1$ to 6$)$ are related by a set of simultaneous algebraic equations (16), which are obtained from Eqs. (11) and (12) and from boundary conditions similar to Eqs. (7a)-(7d).

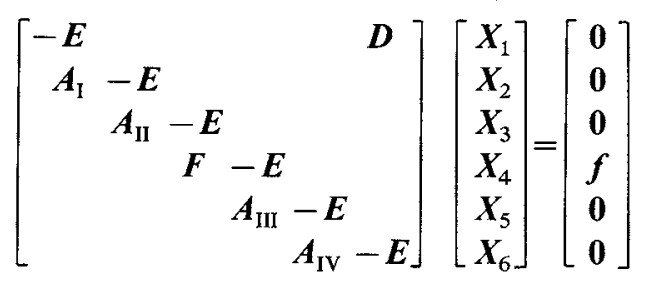

where

$$
\begin{aligned}
\boldsymbol{A}_{\mathrm{n}} & =\left[\begin{array}{cc}
1 & \frac{1-\exp \left\{\alpha_{\mathrm{n}}\left(1-\beta_{\mathrm{nk}}\right) N_{\mathrm{n}}\right\}}{1-\beta_{\mathrm{nk}}} \\
0 & \exp \left\{\alpha_{\mathrm{n}}\left(1-\beta_{\mathrm{nk}}\right) N_{\mathrm{n}}\right\}
\end{array}\right] \\
\boldsymbol{D} & =\left[\begin{array}{cc}
u_{\mathrm{IV}} / u_{\mathrm{I}} & 0 \\
1-u_{\mathrm{IV}} / u_{\mathrm{I}} & 1
\end{array}\right] \\
\boldsymbol{F} & =\left[\begin{array}{cc}
u_{\mathrm{II}} / u_{\mathrm{III}} & 0 \\
1-u_{\mathrm{II}} / u_{\mathrm{III}} & 1
\end{array}\right] \\
\boldsymbol{f} & =\left[\begin{array}{cc}
C_{\mathrm{kf}} \cdot u_{\mathrm{f}} / u_{\mathrm{III}} \\
-C_{\mathrm{kf}} \cdot u_{\mathrm{f}} / u_{\mathrm{III}}
\end{array}\right]
\end{aligned}
$$

and $\boldsymbol{E}$ and $\mathbf{0}$ are unit matrix and zero vector, respectively. The concentration profiles in the adsorber can be calculated by solving Eq. (16). This model 
easily gave the steady-state concentration profiles and was suitable for examining operating conditions.

\section{Adsorption Isotherms and Overall Volumetric Mass Transfer Coefficients of Glucose and Fructose}

The calcium ion form of $\mathrm{Y}$ zeolite (Toyo Soda Mfg.) was used as the adsorbent. The adsorption isotherms of glucose and fructose onto the adsorbent were obtained at $323 \mathrm{~K}$ by using both a batch desorption method and a method in which the breakthrough curve in a packed-bed column was integrated. In the batch desorption method, the adsorbate adsorbed onto the adsorbent was desorbed into a large amount of solvent and its concentration in the solvent was measured to evaluate the amount adsorbed initially $q_{\mathrm{k}} .20 \mathrm{~mol} / \mathrm{m}^{3}$ Tris- $\mathrm{HCl}$ buffer $(\mathrm{pH}$ 8.0 ) containing $10 \mathrm{~mol} / \mathrm{m}^{3}$ magnesium sulfate was used as the solvent.

Glucose and fructose were usually analyzed by using a high-performance liquid chromatograph equipped with a separation column (Shimadzu, SCR$101 \mathrm{~N}$ ) and a differential refractometer. The glucostat method $^{16)}$ and the method of Roe et al. ${ }^{13)}$ were also used to determine glucose and fructose, respectively.

Figure 3 illustrates the measured adsorption isotherms of glucose and fructose for the adsorbent. In the experiments using a mixture of glucose and fructose, the concentrations of both components were initially taken to be equal. The two linear isotherms were obtained for both components over a wide range of concentrations. The amount of fructose adsorbed was independent of that of glucose adsorbed. The distribution coefficients of glucose and fructose onto the adsorbent, $m_{\mathrm{G}}$ and $m_{\mathrm{F}}$, are 0.586 and 0.686 , respectively.

The approximation of a linear driving force was adopted to express the adsorption rate process simply. The overall volumetric mass transfer coefficient $K_{\mathrm{f}} a_{\mathrm{v}}$ was determined so that the calculated breakthrough curve may fit to the experimental one. The $K_{\mathrm{f}} a_{\mathrm{v}}$ values for both glucose and fructose were $6.84 \times 10^{-3} \mathrm{~s}^{-1}$. The values did not change much with the change of eluent flow rate. This suggests that the liquid-phase mass transfer limitation is small.

\section{Experimental Apparatus}

Figure 4 is a schematic diagram of the simulated moving-bed adsorber used. A total of 16 columns, in which $\mathrm{Y}$ zeolite $\left(\mathrm{Ca}^{2+}\right.$ form) was packed, were connected to a rotary valve. Each of the four zones has four columns. Each column is $1.38 \times 10^{-2} \mathrm{~m}$ in diameter and $0.102 \mathrm{~m}$ in length. All columns were kept at $323 \mathrm{~K}$ by circulating thermostatted water through the jackets attached to the columns. The valve consisted of two stainless steel discs. Each flow of liquid through holes in the valve was isolated by using an $\mathrm{O}$ -

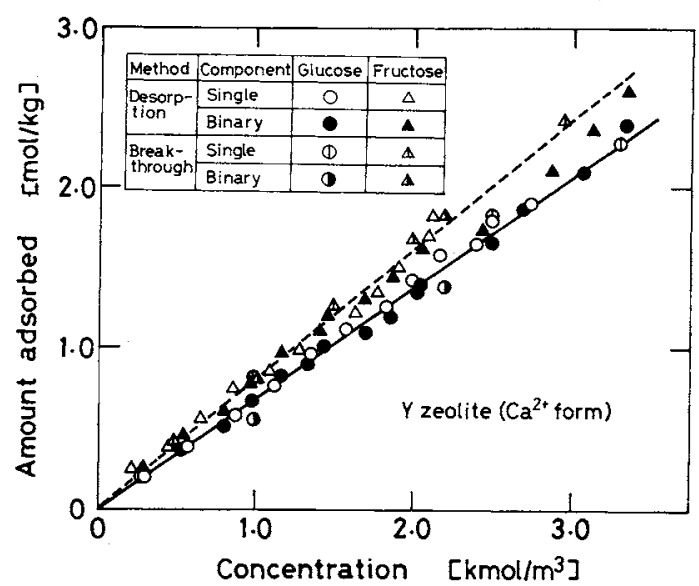

Fig. 3. Adsorption isotherms of glucose and fructose on $Y$ zeolite $\left(\mathrm{Ca}^{2+}\right.$ form $)$ at $323 \mathrm{~K}$.

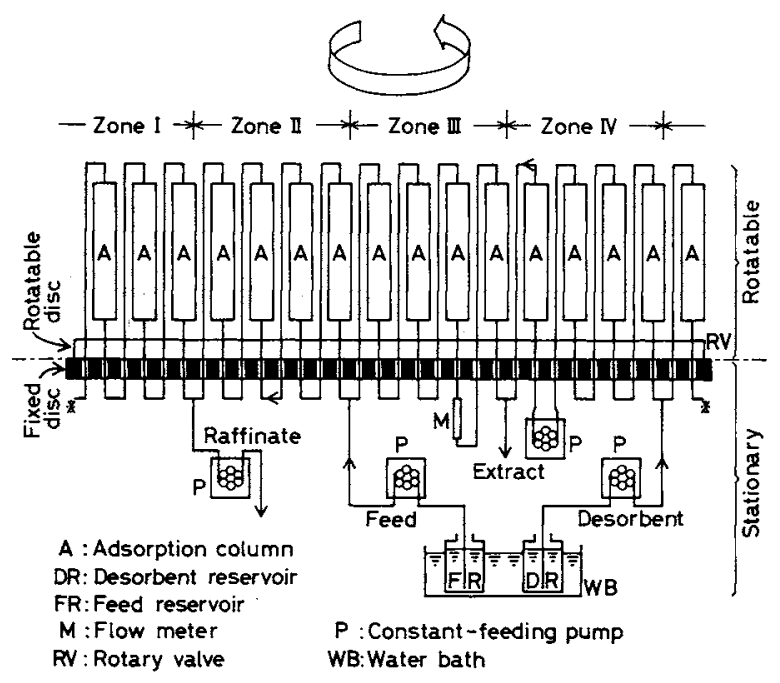

Fig. 4. Schematic diagram of experimental apparatus used in glucose/fructose separation, utilizing a simulated movingbed adsorber.

ring to prevent escape of liquid from the boundary between the discs. The lower disc was stationary, whereas the upper disc could be rotated. The adsorption columns were connected to the upper rotary disc of the valve. The upper disc was rotated counterclockwise by $22.5^{\circ}\left(=360^{\circ} / 16\right)$ at regular intervals $(2$ to $5 \mathrm{~min}$ ). On the other hand, the positions of the raffinate, feed, extract, and desorbent streams were fixed. The intermittent rotation of the upper disc causes counter-current movement of the adsorbent particles to the liquid stream in the columns.

\section{Glucose/Fructose Separation}

The feed solution contained equal amounts of glucose and fructose. They were dissolved in 20 $\mathrm{mol} / \mathrm{m}^{3}$ Tris- $\mathrm{HCl}$ buffer containing $10 \mathrm{~mol} / \mathrm{m}^{3}$ $\mathrm{MgSO}_{4}$. The buffer solution was used as the desorbent. Although the process mentioned here does not require use of the buffer, we used it as a solvent in this study to compare the performance of the simulated moving-bed adsorber with that of the system, 
which will be developed in a separate paper, ${ }^{8)}$ under the same conditions. Prior to the experiment, the liquid in the adsorber was displaced by a solution containing glucose and fructose in the concentration equal to $C_{\mathrm{kf}} \cdot Q_{\mathrm{f}} /\left(Q_{\mathrm{f}}+Q_{\mathrm{d}}\right)$. The raffinate and extract streams were fractionated every $30 \mathrm{~min}$, and the concentrations of glucose and fructose in the fractions were measured. The operation was stopped after establishment of steady state was confirmed. Liquids were sampled from each of the tubes connecting the adsorption columns. Discontinuities in concentration profiles occurred at the introduction points of the feed and desorbent streams, and therefore liquids were sampled specially before and after these points. The concentrations of glucose and fructose in all of these samples were measured. These data points give the concentration profiles of the two components in the adsorber.

Experimental runs were carried out to examine the validity of the models over a wide range of conditions. Table 1 lists operating conditions of some runs. Figure 5 shows the transient changes in the concentrations of glucose and fructose in the extract and raffinate streams in run S-5. The curves in the figure were calculated by using the intermittent moving-bed model. The calculated curves express the experimental results well. Figures 6 and 7 illustrate the concentration profiles at steady state in runs S-5 and S-6. The solid and broken lines in Figs. 6(a) and 7(a) are calculated by using the intermittent moving-bed model, whereas those in Figs. 6(b) and 7(b) are based on the continuous moving-bed model. These figures show that the experimental profiles are in fair agreement with the profiles calculated by the two models in the same degree. These figures do not reveal the appropriateness of the intermittent moving-bed model, which seems to reflect the operating procedure in the experimental apparatus more faithfully than the continuous moving-bed model. Although the reason for the fact mentioned above is not clear, a probable explanation is that assumptions in the intermittent moving-bed model, such as instantaneous transportation of adsorption columns, stepwise changes in liquid flow rates at boundaries of zones, and plug flow of liquid, are not exactly satisfied in the experimental apparatus. The intermittent moving-bed model gives transient changes in the profiles and predicts the time needed to reach steady state, while the continuous moving-bed model conveniently gives the steady-state profiles and is useful in examining operating conditions for good separation. Thus, the two models have different roles and both are considered useful for the design of the simulated moving-bed adsorber.

\section{Criterion for Good Separation}

The parameter, $\beta_{\mathrm{nk}}$, in the continuous moving-bed
Table 1. Experimental conditions for separating glucose and fructose by using the simulated moving-bed adsorber packed with $\mathrm{Y}$ zeolite $\left(\mathrm{Ca}^{2+}\right.$ form $)$

\begin{tabular}{|c|c|c|c|c|c|}
\hline \multicolumn{2}{|c|}{ Run No. } & \multirow{2}{*}{$\frac{\mathrm{S}-3^{*}}{100}$} & \multirow{2}{*}{$\frac{\mathrm{S}-5}{500}$} & \multirow{2}{*}{$\begin{array}{r}\text { S-6 } \\
500\end{array}$} & \multirow{2}{*}{$\frac{\text { S-7 }}{1000}$} \\
\hline$G_{\mathrm{Gf}}$ & {$\left[\mathrm{mol} / \mathrm{m}^{3}\right]$} & & & & \\
\hline$C_{\mathrm{Ff}}$ & {$\left[\mathrm{mol} / \mathrm{m}^{3}\right]$} & 100 & 500 & 500 & 1000 \\
\hline$Q_{\mathrm{f}} \times 10^{8}$ & {$\left[\mathrm{~m}^{3} / \mathrm{s}\right]$} & 1.00 & 1.67 & 0.67 & 0.67 \\
\hline$Q_{\mathrm{d}} \times 10^{8}$ & {$\left[\mathrm{~m}^{3} / \mathrm{s}\right]$} & 3.00 & 5.00 & 2.67 & 3.33 \\
\hline$Q_{\mathrm{r}} \times 10^{8}$ & {$\left[\mathrm{~m}^{3} / \mathrm{s}\right]$} & 2.00 & 3.33 & 1.67 & 2.00 \\
\hline$Q_{\mathrm{e}} \times 10^{8}$ & {$\left[\mathrm{~m}^{3} / \mathrm{s}\right]$} & 2.00 & 3.33 & 1.67 & 2.00 \\
\hline$T$ & [s] & 120 & 120 & 120 & 120 \\
\hline$v_{1} \times 10^{4}$ & {$[\mathrm{~m} / \mathrm{s}]$} & 5.57 & 5.13 & 5.06 & 4.75 \\
\hline$v_{\mathrm{II}} \times 10^{4}$ & {$[\mathrm{~m} / \mathrm{s}]$} & 6.90 & 7.89 & 6.17 & 6.08 \\
\hline$v_{\mathrm{III}} \times 10^{4}$ & {$[\mathrm{~m} / \mathrm{s}]$} & 6.23 & 6.17 & 5.73 & 5.64 \\
\hline$v_{\mathrm{IV}} \times 10^{4}$ & {$[\mathrm{~m} / \mathrm{s}]$} & 7.57 & 8.40 & 6.84 & 6.97 \\
\hline
\end{tabular}

* Another lot of $\mathrm{Y}$ zeolite $\left(\mathrm{Ca}^{2+}\right.$ form) was used $\left(m_{\mathrm{G}}=0.518\right.$ and $m_{\mathrm{F}}=0.743$ ).

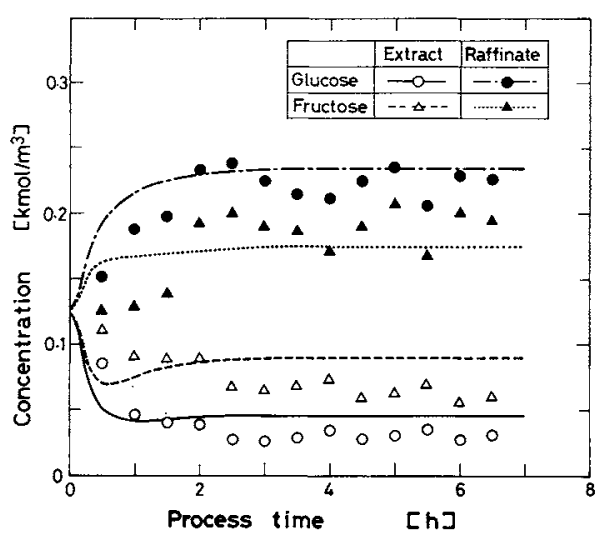

Fig. 5. Time courses of glucose and fructose concentrations in extract and raffinate streams in run S-5.

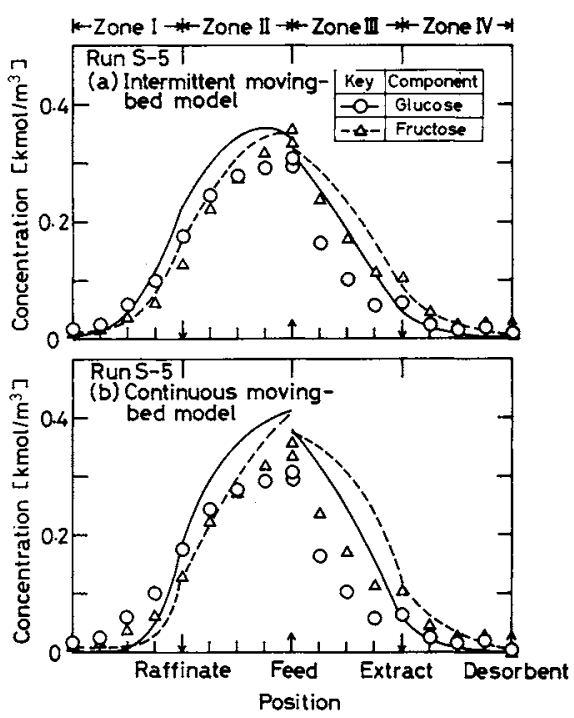

Fig. 6. Concentration profiles of glucose and fructose in the adsorber at steady state in run S-5.

model was originally defined by Eq. (13b). The physical meaning of the parameter is given as follows: 


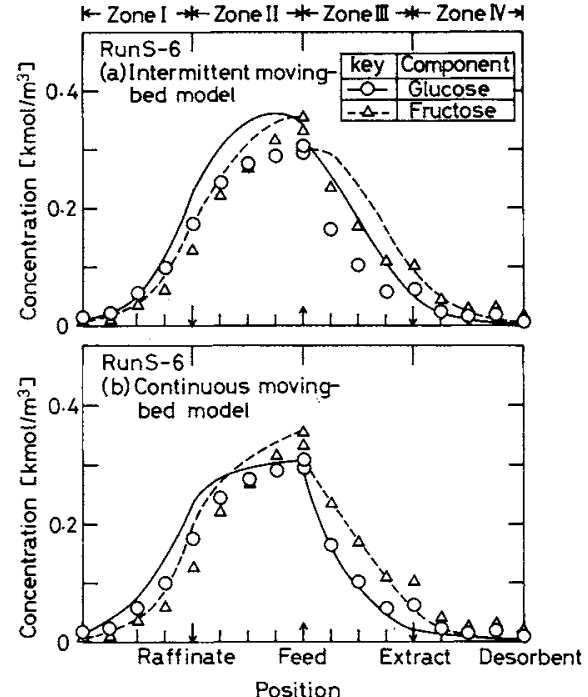

Fig. 7. Concentration profiles of glucose and fructose in the adsorber at steady state in run S-6.

$$
\beta_{\mathrm{nk}}=\frac{u_{\mathrm{n}}}{u_{\mathrm{s}}\left(1-\varepsilon_{\mathrm{b}}\right) m_{\mathrm{k}}}=\frac{\left\{\begin{array}{l}
\text { amount of adsorbate trans- } \\
\text { ported by fluid phase }
\end{array}\right\}}{\left\{\begin{array}{l}
\text { amount of adsorbate trans- } \\
\text { ported by solid phase }
\end{array}\right\}}
$$

When $\beta_{\mathrm{nk}}$ is less than unity, the amount of adsorbate carried by the adsorbent flow is more than that carried by the liquid flow. The range of $\beta_{\mathrm{nk}}$ allowable to obtain good separation must be set in the mode shown in Table 2. For example, the parameter for fructose in zone II, $\beta_{\mathrm{IIF}}$, should be less than unity because the fructose must be selectively adsorbed on the solid phase and conveyed to zones III and IV. On the other hand, glucose in the liquid phase of zone II is not adsorbed and is withdrawn by the raffinate stream, and hence the value of $\beta_{\mathrm{IIG}}$ should be larger than 1.0 .

Figure 8(a) and (b) illustrate the effect of $\beta_{\text {nk }}$ on the separation. The concentration profiles obtained experimentally in run S-3 are shown in Fig. 8(a) along with the ones calculated by using the continuous moving-bed model. The $\beta_{\text {nk }}$ values in run S-3 satisfy the criteria in Table 2, and a good separation was achieved. On the other hand, Fig. 8(b) shows the concentration profiles obtained in run S-7, where $\beta_{\mathrm{nk}}$ values do not satisfy the criteria.

The importance of $\beta_{\mathrm{nk}}$ values is also clear in the intermittent moving-bed model. Barker et al. ${ }^{1,2)}$ discussed the operating conditions for the separation process using sequential chromatographic equipment. The operating conditions for glucose/fructose separation using the simulated moving-bed adsorber are explained by adopting a similar approach. An average migration rate of the adsorption wave of component $\mathrm{k}$ in zone $\mathrm{n}, \bar{v}_{\mathrm{nk}}$, is given approximately by the following equation. ${ }^{12,14)}$
Table 2. $\beta_{\text {nk }}$ values necessary to obtain high separability

\begin{tabular}{ccccc}
\hline Zone n & I & II & III & IV \\
\hline$\beta_{\mathrm{nG}}$ & $<1$ & $>1$ & $>1$ & $>1$ \\
$\beta_{\mathrm{nF}}$ & $<1$ & $<1$ & $<1$ & $>1$ \\
\hline
\end{tabular}

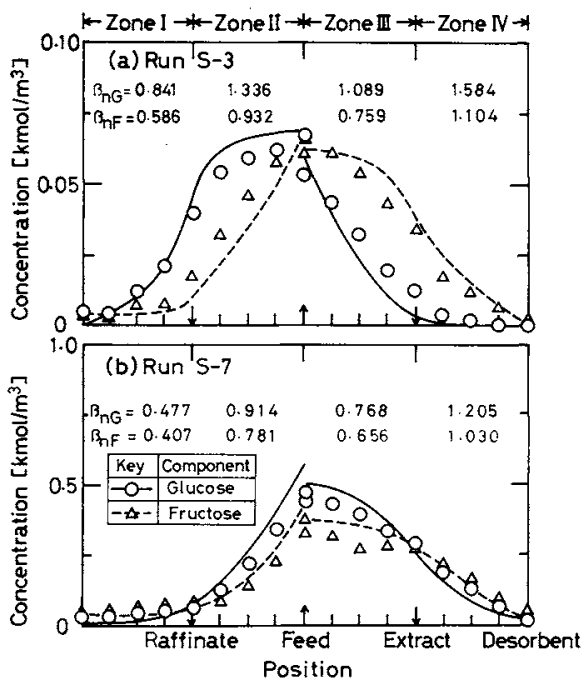

Fig. 8. Importance of $\beta_{\mathrm{nk}}$ values in obtaining high separability.

$$
\bar{v}_{\mathrm{nk}}=v_{\mathrm{n}} /\left\{\varepsilon_{\mathrm{b}}+\left(1-\varepsilon_{\mathrm{b}}\right) m_{\mathrm{k}}\right\}
$$

For example, we consider what is the condition in which zone II plays its correct function. The primary object of zone II is the selective adsorption of fructose. When zone II consists of $N_{\mathrm{II}}$ columns, the length of the zone is $N_{\mathrm{II}} L_{\mathrm{A}}$ and the period required to accomplish the displacement of the whole column in zone II is $N_{\mathrm{II}} T$. the adsorption wave of glucose must have already reached the end point of zone II before the replacement of all columns in the zone is finished, while the adsorption wave of fructose should still be within the zone. Thus, the following inequalities must hold in order to withdraw only glucose in the raffinate stream.

$$
\begin{aligned}
& N_{\mathrm{II}} L_{\mathrm{A}}<N_{\mathrm{II}} T \cdot v_{\mathrm{II}} /\left\{\varepsilon_{\mathrm{b}}+\left(1-\varepsilon_{\mathrm{b}}\right) m_{\mathrm{G}}\right\} \\
& N_{\mathrm{II}} L_{\mathrm{A}}>N_{\mathrm{II}} T \cdot v_{\mathrm{II}} /\left\{\varepsilon_{\mathrm{b}}+\left(1-\varepsilon_{\mathrm{b}}\right) m_{\mathrm{F}}\right\}
\end{aligned}
$$

By using the relations of $u_{\mathrm{n}}=v_{\mathrm{n}}-\varepsilon_{\mathrm{b}} L_{\mathrm{A}} / T$ and $u_{\mathrm{s}}=L_{\mathrm{A}} / T$, Eqs. (20) and (21) are rearranged to give

$$
\begin{aligned}
& 1<u_{\mathrm{II}} /\left\{u_{\mathrm{s}}\left(1-\varepsilon_{\mathrm{b}}\right) m_{\mathrm{G}}\right\} \\
& 1>u_{\mathrm{II}} /\left\{u_{\mathrm{s}}\left(1-\varepsilon_{\mathrm{b}}\right) m_{\mathrm{F}}\right\}
\end{aligned}
$$

The right sides of Eqs. (22) and (23) are equal to the definition of $\beta_{\mathrm{IIk}}$. Similar considerations are given for the other zones and the relationships in Table 2 are derived. We can rearrange the relationships listed in Table 2 to yield the following inequality, which gives the relationships among the liquid flow rates in each of the four zones. 


$$
\begin{aligned}
v_{\mathrm{I}}<\left(L_{\mathrm{A}} / T\right) & \cdot\left\{\varepsilon_{\mathrm{b}}+\left(1-\varepsilon_{\mathrm{b}}\right) m_{\mathrm{G}}\right\}<v_{\mathrm{III}}<v_{\mathrm{II}} \\
& <\left(L_{\mathrm{A}} / T\right) \cdot\left\{\varepsilon_{\mathrm{b}}+\left(1-\varepsilon_{\mathrm{b}}\right) m_{\Gamma}\right\}<v_{\mathrm{IV}}
\end{aligned}
$$

The simulated moving-bed adsorber can separate glucose and fructose under the conditions where the flow rates in each zone are set to satisfy Eq. (24), even if the difference between $m_{\mathrm{G}}$ and $m_{\mathrm{F}}$ is not so large.

In this study, it was assumed that the adsorption isotherm of a component was linear and independent of that of another coexisting component. The validity of this assumption was experimentally verified for the separation of glucose/fructose mixture. The assumption, however, may not always be satisfied for other cases. When the adsorption isotherm of any component is non-linear, the steady-state concentration profile of the component in the simulated moving-bed adsorber can be calculated through a method of quasilinearization technique. ${ }^{10)}$

\section{Conclusion}

1. Two mathematical models are presented for calculating the concentration profiles of glucose and fructose in a simulated moving-bed adsorber. One model, called an intermittent moving-bed model, faithfully expressed the manner of operation of the adsorber and was useful in calculating the unsteadystate profiles. The other model was derived by assuming a continuous movement of adsorbent and was named the continuous moving-bed model. The use of this model gave the steady state profiles simply and facilitated the examination of operating conditions.

2. A continuous separation of glucose and fructose was experimentally performed by using the simulated moving-bed adsorber. The counter-current movement of the adsorbent to liquid flow was realized by using a specially-designed multi-port type of rotary valve.

3. It was shown that a dimensionless parameter $\beta_{\text {nk }}$ defined in the continuous moving-bed model played an important role in determining operating conditions. The criterion of $\beta_{\mathrm{nk}}$ has to be met for attaining a good separation of glucose and fructose.

4. It was found that the $\mathrm{Ca}^{2+}$ ion form of $\mathrm{Y}$ zeolite adsorbed fructose preferentially. The adsorption isotherms of glucose and fructose on the adsorbent were linear and independent of each other.

\section{Acknowledgment}

This work was supported partly by a Grant-in-Aid for Developmental Scientific Research (Project Number: 00585245) from the Ministry of Education, Science and Culture of Japan.

\section{Nomenclature}

\begin{tabular}{|c|c|c|}
\hline$K_{\mathrm{f}}$ & $=$ overall mass transfer coefficient & {$[\mathrm{m} / \mathrm{s}]$} \\
\hline$L_{\mathrm{A}}$ & $=$ length of each adsorption column & {$[\mathrm{m}]$} \\
\hline$m$ & $=$ distribution coefficient & {$[-]$} \\
\hline$N$ & $=$ number of columns in any zone & {$[-]$} \\
\hline$Q$ & $=$ volumetric flow rate & {$\left[\mathrm{m}^{3} / \mathrm{s}\right]$} \\
\hline$q$ & $=$ amount adsorbed & {$[\mathrm{mol} / \mathrm{kg}]$} \\
\hline$T$ & $\begin{aligned}= & \text { interval of transportation of adsorption } \\
& \text { columns }\end{aligned}$ & [s] \\
\hline$t$ & $=$ time & [s] \\
\hline$u$ & $\begin{aligned}= & \text { superficial velocity of liquid flow in the } \\
& \text { hypothetical moving bed }\end{aligned}$ & {$[\mathrm{m} / \mathrm{s}]$} \\
\hline$u_{\mathrm{s}}$ & $=$ velocity of adsorbent flow & {$[\mathrm{m} / \mathrm{s}]$} \\
\hline$v$ & $\begin{array}{l}=\text { superficial velocity of liquid flow in the } \\
\text { fixed bed }\end{array}$ & {$[\mathrm{m} / \mathrm{s}]$} \\
\hline $\bar{v}$ & $\begin{array}{l}=\text { average migration rate of the adsorption } \\
\text { wave }\end{array}$ & {$[\mathrm{m} / \mathrm{s}]$} \\
\hline$x$ & $=z / L_{\mathbf{A}}$ & {$[-]$} \\
\hline$z$ & $=$ axial distance & {$[\mathrm{m}]$} \\
\hline$\alpha_{\mathrm{n}}$ & $=K_{\mathrm{f}} a_{\mathrm{v}} L_{\mathrm{A}} / u_{\mathrm{n}}$ & {$[-]$} \\
\hline$\beta_{\mathrm{nk}}$ & $=u_{\mathrm{n}} /\left\{u_{\mathrm{s}}\left(1-\varepsilon_{\mathrm{b}}\right) m_{\mathrm{k}}\right\}$ & {$[-]$} \\
\hline$\varepsilon_{\mathrm{b}}$ & $=$ void fraction of the bed & {$[-]$} \\
\hline$\theta$ & $=t / T$ & {$[-]$} \\
\hline$\lambda_{\mathrm{n}}$ & $=v_{\mathrm{n}} T /\left(\varepsilon_{\mathrm{b}} L_{\mathrm{A}}\right)$ & {$[-]$} \\
\hline$\phi$ & $=K_{\mathrm{f}} a_{\mathrm{v}} T / \varepsilon_{\mathrm{b}}$ & {$[-]$} \\
\hline$\psi_{\mathbf{k}}$ & $=K_{\mathrm{f}} a_{\mathrm{v}} T /\left\{\left(1-\varepsilon_{\mathrm{b}}\right) m_{\mathrm{k}}\right\}$ & {$[-]$} \\
\hline
\end{tabular}

$$
\begin{array}{llr}
a_{\mathrm{v}} & =\text { specific surface area } & {\left[\mathrm{m}^{2} / \mathrm{m}^{3}-\mathrm{bed}\right]} \\
C & =\text { concentration in the mobile phase } & {\left[\mathrm{mol} / \mathrm{m}^{3}\right]} \\
C^{*} & =\text { concentration in the stationary phase } & {\left[\mathrm{mol} / \mathrm{m}^{3}\right]} \\
\bar{C}^{*} & =C-C^{*} & {\left[\mathrm{~mol} / \mathrm{m}^{3}\right]}
\end{array}
$$

〈Subscripts〉

$$
\begin{aligned}
& \mathrm{d}=\text { desorbent } \\
& \mathrm{F} \quad=\text { fructose } \\
& \mathrm{f} \quad=\text { feed } \\
& \text { G } \quad=\text { glucose } \\
& \mathrm{k}=\text { arbitrary component } \\
& 1=\text { outlet } \\
& \mathrm{n} \quad=\text { zone number (=I to IV) } \\
& 0=\text { inlet }
\end{aligned}
$$

\section{Literature Cited}

1) Barker, P. E. and C. B. Ching: Kemtek 5, 5th International Congress on Chemical Engineering European Federation of Chemical Engineering, April 1980, Copenhagen.

2) Barker, P. E., B. W. Hatt and A. N. Williams: Chromatographia, 10, 370 (1977).

3) Broughton, D. B.: U. S. Patent, 2,985,589 (1961)

4) Broughton, D. B., H. J. Bieser, M. C. Anderson and R. A. Persak: Kagakukeizai, Feb., p. 54 (1976).

5) Broughton, D. B., R. W. Neuzil, J. M. Pharis and C. S. Brearly: Chem. Eng. Prog., 66, 70 (1970).

6) Glueckauf, E.: Trans. Faraday Soc., 51, 1540 (1955).

7) Goulding, R. W.: J. Chromatogr., 103, 229 (1975).

8) Hashimoto, K., S. Adachi, H. Noujima and Y. Ueda: Biotechnol. Bioeng., 25 (1983) (in press).

9) Kainuma, K., K. Yoritomi, and T. Komaki: "Denpunkagaku Hand Book," ed. by J. Nikuni, M. Nakamura and S. Suzuki, Asakurashoten, Tokyo, p. 489 (1977).

10) Lee, E. S.: AIChE J., 14, 490 (1968).

11) Miura, K. and K. Hashimoto: J. Chem. Eng. Japan, 10, 490 (1977).

12) Nakanishi, K., S. Yamamoto, R. Matsuno and T. Kamikubo: Agric. Biol. Chem., 17, 1515 (1975).

13) Roe, J. H., J. H. Epotein and N. P. Goldstein: J. Biol. Chem., 178, 839 (1949).

14) Suzuki, M.: Seisankenkyu, 24, 187 (1972).

15) Takasaki, Y.: Agric. Biol. Chem., 31, 309 (1967).

16) Toren, Jr. E. C.: J. Chem. Educ., 44, 172 (1967).

17) Treybal, R. E.: "Mass-Transfer Operations," 3rd ed., McGraw-Hill-Kogakusha, Tokyo, p. 622 (1980). 